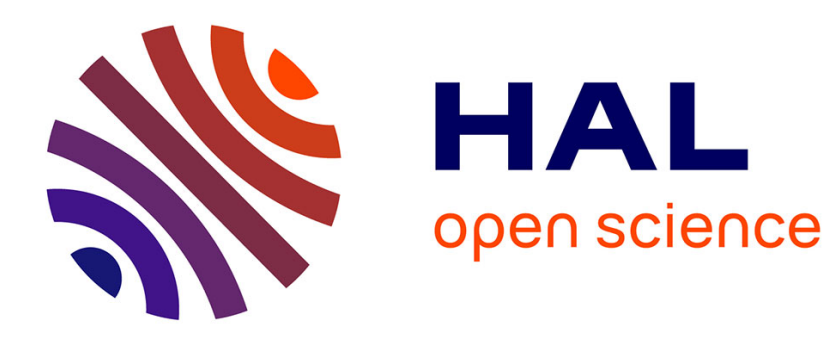

\title{
Subcritical Crack Growth in MnZn Ferrites
}

\author{
M. Donners, L. Dortmans, G. de With, M. de Graaf
}

\section{To cite this version:}

M. Donners, L. Dortmans, G. de With, M. de Graaf. Subcritical Crack Growth in MnZn Ferrites. Journal de Physique IV Proceedings, 1997, 07 (C1), pp.C1-263-C1-264. 10.1051/jp4:19971102 . jpa00254723

\section{HAL Id: jpa-00254723 \\ https://hal.science/jpa-00254723}

Submitted on 1 Jan 1997

HAL is a multi-disciplinary open access archive for the deposit and dissemination of scientific research documents, whether they are published or not. The documents may come from teaching and research institutions in France or abroad, or from public or private research centers.
L'archive ouverte pluridisciplinaire $\mathbf{H A L}$, est destinée au dépôt et à la diffusion de documents scientifiques de niveau recherche, publiés ou non, émanant des établissements d'enseignement et de recherche français ou étrangers, des laboratoires publics ou privés. 


\title{
Subcritical Crack Growth in MnZn Ferrites
}

\author{
M. Donners, L. Dortmans, G. de With and M. de Graaf* \\ Centre for Technical Ceramics, P.O. Box 595, 5600 AN Eindhoven, The Netherlands \\ * Philips Components, BU Magnetic Products, P.O. Box 218, 5600 MD Eindhoven, The Netherlands
}

\begin{abstract}
In order to establish the influence subcritical crack growth (SCG) has on the mechanical behaviour of commercial $\mathrm{MnZn}$ ferrites, both constant stress rate (CSR) and constant load (CL) tests were performed on $\mathrm{E} 42$ cores using the W test. All tests were done at room temperature and under a controlled humidity or submerged in water. Increasing humidity decreases strength and lifetime. In CSR tests with increasing stress rate, strength increases. In CL tests at two different humidities, a threshold at about $75 \%$ of the inert strength seems to limit the effect of SCG. The strength of these cores in W tests depends on the behaviour of only two kinds of defects. The fraction of the cores failing on either kind depends on stress rate and humidity. These two factors also influence the fracture mode, in these tests increasing from 35 to $62 \%$ transgranular fracture with increasing humidity and decreasing loading rate.
\end{abstract}

\section{INTRODUCTION}

To determine the mechanical strength and subcritical crack growth (SCG) behaviour of soft ferrite components, mechanical tests were performed on a commercial MnZn ferrite. The iron excess ferrite had a density of $4.8 \mathrm{~g} / \mathrm{cm}^{3}$ and a mean grain size of about $8 \mu \mathrm{m}$. The tests were performed on $\mathrm{E}$ cores, of 42 by 21 by $15 \mathrm{~mm}$.

All cores were subjected to the so-called W test, in which case the tensile stresses are located at the back of the core [1]. They were performed with either a constant stressing rate (CSR) or with a constant load (CL), measuring strength and lifetime respectively. All tests were performed at room temperature, in an atmosphere with controlled humidity, ranging from 2.4 to $100 \%$ relative humidity $(\mathrm{RH})$ or in water. Fractography was applied in order to identify the initial defect or to establish the fracture mode (i.e. trans- or intergranular crack growth).

\section{RESULTS AND DISCUSSION}

\subsection{CSR tests}

The mechanical strength decreases with decreasing stress rate and with increasing humidity, showing the influence of SCG. Figure 1 shows the influence of the relative humidity on the actual strength, $\sigma_{f}$ - relative to the inert strength, $S_{f}$ - at three stress rates $\dot{\sigma}$. The data is fitted using a relation between strength and water vapour pressure in the environment $p_{w}$ :

$$
\mathrm{S}_{\mathrm{f}}^{\mathrm{n}-2}=\sigma_{\mathrm{f}}^{\mathrm{n}-2}+\mathrm{p}_{\mathrm{w}}^{\eta} \frac{\mathrm{A}}{\dot{\sigma}} \sigma_{\mathrm{f}}^{\mathrm{n}+1}
$$

using the parameters $S_{f}, n, \eta$ and $A$. This equation results from introducing the water vapour pressure as a separate preexponential factor in the power law normally used to describe SCG [2]:

$$
\frac{\partial \mathrm{a}}{\partial \mathrm{t}}=\mathrm{A} \cdot \mathrm{p}_{\mathrm{w}}^{\eta} \cdot\left(\frac{\mathrm{K}_{\mathrm{I}}}{\mathrm{K}_{\mathrm{Ic}}}\right)^{\mathrm{n}}
$$

using the partial derivative of crack length, a, to time, $t$, the stress intensity, $K_{1}$ and the fracture toughness, $K_{I c}$. At higher stress rates the water concentration at the crack tip will lessen as the supply of water by diffusion is outrun by the increasing crack growth rate. The parameter $\eta$ was found to be about 2 for all the stress rates. This could mean that a reaction, pseudo second order in water, controls SCG. Note that at the two highest stress rates this fit over-estimates the strength at $20 \% \mathrm{RH}$ and under-estimates it at 70 to $80 \% \mathrm{RH}$. 


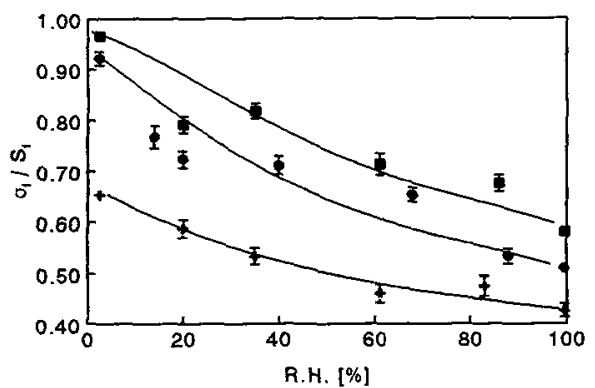

Figure 1. Fracture stress $\sigma_{\mathrm{f}}$ (relative to inert strength $\mathrm{S}_{\mathrm{f}}$ ) versus relative humidity at three stressing rates $(+: 0.43 \mathrm{MPa} / \mathrm{s}, \bullet: 8.3 \mathrm{MPa} / \mathrm{s}, \quad: 83 \mathrm{MPa} / \mathrm{s})$.

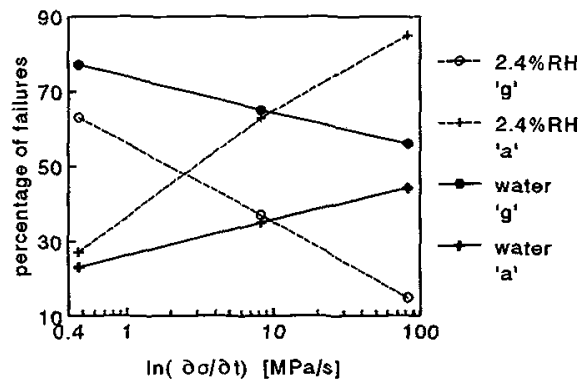

Figure 2. Percentage of failures on defects of types ' $\mathrm{a}$ ' $(+,+)$ and ' $\mathrm{g}$ ' $(0, \bullet)$ in air of $2.4 \% \mathrm{RH}$ or submerged in water, respectively.

Fractographical analysis of these cores has shown that their strength is limited by only two types of defects: excessively large grown grains and large pores surrounding agglomerates, denoted by ' $\mathrm{g}$ ' and ' $a$ ', respectively. To be able to give a correct statistical description, a bimodal strength distribution was used. At low stressing rates the majority of the cores fails on defects of type ' $\mathrm{g}$ ', the exact ratio depending on the humidity $63 \%$ at $2.4 \% \mathrm{RH}$ against $77 \%$ when submerged in water). Increasing the stressing rate decreases the fraction of failures on defects ' $\mathrm{g}$ ' to $13 \%$ and $56 \%$ respectively (figure 2).

At the lowest stressing rate the percentage of transgranular fracture increases from 35 to 62 with humidity increasing from 2.4 to $100 \% \mathrm{RH}$. At higher stressing rates a similar increase is found, but it is then limited to $52 \%$ transgranular fracture.

\section{2,2 CL tests}

In air of $2.4 \% \mathrm{RH}$ and at applied stresses higher than about $75 \%$ of the inert strength, the time-to-failure decreases with increasing applied stress as expected using the power law normally used to describe SCG [2] (SCG parameter $\mathbf{n} \approx 7$ ). At lower stresses however, lifetimes are much longer than expected, As many of the tests at these relatively low loads had to be aborted, the true mean values are even larger.

In air of $50 \% \mathrm{RH}$, at applied stresses between 65 and $75 \%$ of $\mathrm{S}_{\mathrm{f}}$, lifetime decreases with increasing stress level, similar to the behaviour at $2.4 \% \mathrm{RH}$. At lower stresses lifetimes are again much larger than expected. This could mean that a threshold to SCG exists. In both cases the threshold stress would be 25 to $30 \%$ lower than the critical stress at that humidity. No fractography was applied to these cores.

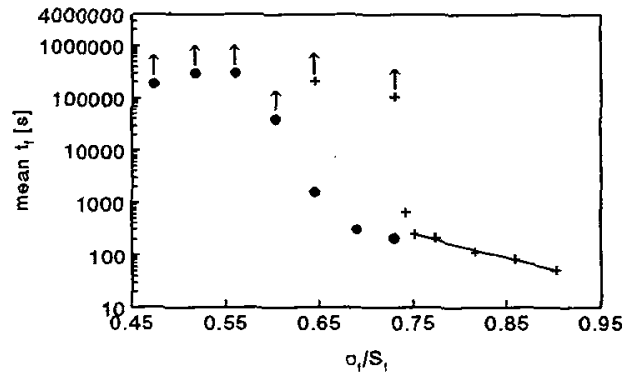

Figure 3. Mean lifetime $t_{\mathrm{f}}$ versus applied stress $\sigma_{\mathrm{f}}$ (relative to inert strength $S_{\mathrm{f}}$ ) in air of $2.4 \% \mathrm{RH}(t)$ and of $50 \% \mathrm{RH}(\bullet)$.

\section{CONCLUSIONS}

It has been shown in both constant load and constant stress rate tests that $\mathrm{MnZn}$ ferrites are susceptible to subcritical crack growth. Both the humidity of the atmosphere and the loading rate influence the mechanical behaviour. It is important to consider these effects when reporting on or comparing strength tests of ferrites. At low stress rates the effect of the humidity can be described by modifying the standard power law model of SCG. At somewhat higher stress rates this becomes impossible due to the rate limiting effect of the diffusion of water from the atmosphere to the crack tip. Both this effect and the possible presence of a threshold to SCG in MnZn ferrites will be included in future work.

[1] de Graaf M., Beck, E., Dortmans, L., "Mechanical Reliability of ferrite cores: Thermomechanical stresses in operation and in strength tests", Proceedings Electroceramics IV, Aachen, 1994

[2] Munz D., Fett T., Mechanisches Verhalten keramischer Werkstoffe (Springer Verlag, Berlin, 1989) pp. 45-65 